ISSN 1112-9867

http://www.jfas.info

\title{
EXPERIMENTAL INVESTIGATION OF NANO-ALUMINA EFFECT ON THE FILLING TIME IN VARTM PROCESS
}

\author{
P. Ghabezi ${ }^{1}$, M. Farahani ${ }^{1 *}$, M. Hosseini fakhr ${ }^{2}$ \\ ${ }^{1}$ School of Mechanical Engineering, College of Engineering, University of Tehran \\ ${ }^{2}$ MSc, Student, Faculty of Mechanical Engineering, Islamic Azad university, Sari branch
}

Published online: 18 June 2016

\begin{abstract}
In this research, by producing composite samples made of glass fibers and epoxy resin with different percentages of nanoparticles (Nano-alumina), the adding effect of nanoparticles of alumina Alpha and Gamma grade on filling time in the vacuum assistant resin transfer molding process (VARTM) is investigated. The grade Alpha and Gamma of Nano alumina were added to the epoxy system with the weight percentage of $1,2,3,4,5$ and 6 . The experimental results show that increasing nanoparticles lead to increase the filling time which is caused by increased fluid viscosity and consequently more resistant to vacuum pressure applied to flow fluid in porous media of preforms. By adding of nanoparticles, an optimal limit exists to prevent a significant increase in the filling time which is $3 \%$ for Nano-composite samples of alumina with grade of Alpha and Gamma. Also, in the first, the movement speed of the resin into the preform is about one centimeter per second, and by increasing flow this speed gradually decreases (close to zero).
\end{abstract}

Keywords: Nano-composite, VARTM, Nano-Alumina, displacement-time curve, die filling time

Author Correspondence, e-mail: mrfarahani@ut.ac.ir

doi: http://dx.doi.org/10.4314/jfas.v8i2s.146 


\section{INTRODUCTION}

In the recent years, the importance of using modern methods in the production of composite parts has attracted the attention of many researchers in this field. In addition, the importance of building lighter structures with more engineering capabilities has led researchers to activities of. Nano-technology the use of nanoparticles in the manufacture of composite samples by suction method is a new field which there has been little research in the composite industry. One of the production methods of composites is resin transfer molding (RTM) which is subset of a broader category called liquid composite molding (LCM). This process was used for the first time in the early 1940s by the United States Navy for the construction of reinforced plastic boats. In the early 1950s in the UK, various industries used the injection process as a more advanced way compared to manual padding method. Nowadays, special and unique properties of the injection process attract the attention of more manufacturers in the composites industry. So far, various forms of injection process are presented and used. The most important of them is vacuum assistant resin transfer molding. The advantages of suction method are high quality, decrease of bubbles and increase of volume percentage of fiber in constructed parts. Wan et al in their study showed that parts constructed by suction method have fewer bubbles than the manual method [1]. The investigations of Kav showed that the decrease of 2 to $10 \%$ in mechanical properties is generally visible by increasing each $1 \%$ bubble [2]. Ninak Kuentzer et al showed that by increasing the amount of vacuum and letting out bubbles and resin after the completion of injection process, the amount of bubbles in the composite pieces is reduced [3].

The spread of nanotechnology and use it in polymer composites has created promising progress towards the production of new materials for structural applications. More research conducted into Nano materials with a polymer matrix, reinforced with fibers, to improve the mechanical properties.

Gilbert et al [4] and Timmerman et al. [5] showed that the fracture toughness had been improved by adding metal nanoparticles and Nano clay. Yasmin et al [6] reported an increase of about $80 \%$ in elastic modulus while adding 1 to $10 \mathrm{wt} \%$ of closed CB in epoxy. Lin et al [7] also reported a $30 \%$ increase in impact resistance when using closed CB of $50 \mathrm{wt} \%$ in epoxy 
resin. Rice et al [8] used organic silicate for reinforcing epoxy/carbon fiber, added $2 \mathrm{wt} \%$ of Nano-filler and observed a $12 \%$ improvement in hardness compared to pure epoxy. Chowd hury et al. [9] studied mechanical and thermal properties of polymer composite with woven carbon fiber using vacuum assistant resin transfer molding. They added modified mineral montmorillonite with different weight percentages to epoxy. Epoxy with Nano phase was used for producing composite with carbon fiber that the results of bending test for samples cooked at high temperature showed the greatest improvements in strength and hardness, $14 \%$ and 9\%, respectively. According to the results of fracture test for a sample with no fiber and investigation of SEM images, Brunner et al [10] concluded that resistance to lamination in composite with resin modified using Nano clay.

Karaki et al [11] added layer Nano clay, alumina and titanium dioxide added into the epoxy matrix and examined the fatigue behavior of hybrid carbon fiber composite material. They concluded that the number of micro-cracks depends on the type filler particles and their concentration.

Gojny et al [12] had a comprehensive review on the impact of Nano fillers on the fracture toughness of epoxy resins and related Micro-mechanism. They studied the hardening mechanisms in two-dimensional plot: 1. Micromechanical mechanisms such as deformation of cracks in agglomerates, stretching in the deformation range of plastic and so on, 2 . Nano-mechanical mechanisms such as the separation of levels, protrusions and bridging of cracks in the presence of carbon nanoparticles.

Adding Nano fibers of alumina into epoxy glue causes a small increase in the bonding strength of aluminum samples but the effect of Nano amplifiers on bonding toughness of carbon/epoxy composite is considerable and also different depending on the construction method of samples as prefabricated and co-cured. The figure below shows the results obtained by them $[13,14]$. 


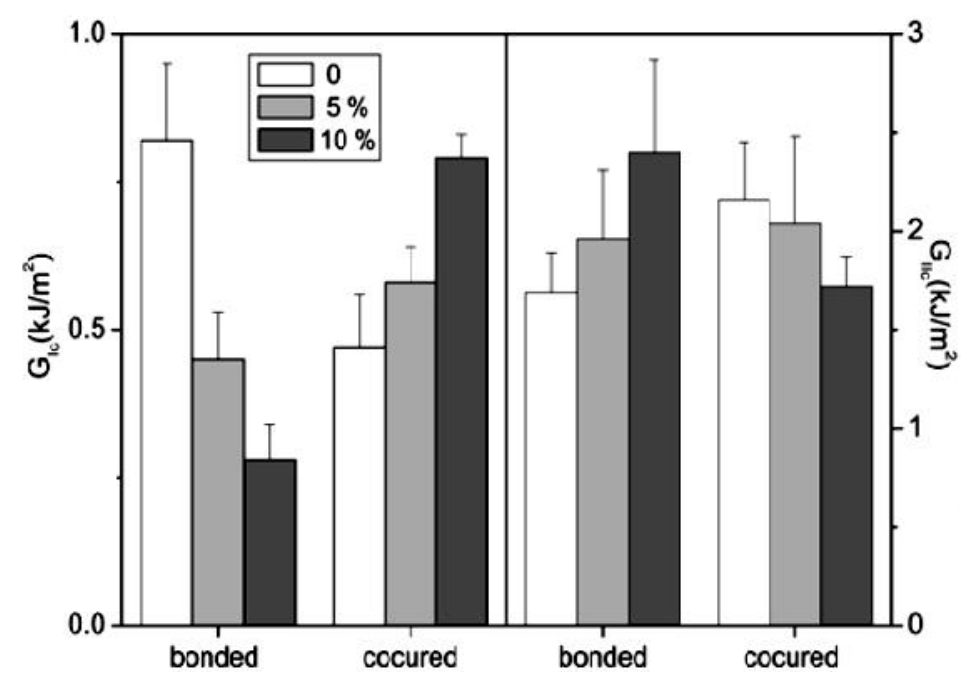

Fig.1. Effect of alumina particles on the properties of the adhesive bond strength [13].

Zhai et al conducted some research in the field of adding nano alumina into epoxy resin to attach the steel samples $[15,16]$.

According to the research conducted regarding the use of nanoparticles in composite materials, it can be received that there was too little attention to making composites using VARTM during adding nanoparticles. Therefore, in this study, the purpose is to investigate the filling behavior of die during the resin injection with different percentages of nano alumina particles Alpha and Gamma grade and its impact on filling time of die and its constraints. Since nowadays the adoption of modern methods of composite construction such as VARTM is increasing, it is essential to understand and optimize their behavior.

\section{EXPERIMENTS}

\subsection{Material}

Nano-composites used in this study were glass/epoxy reinforced with nano alumina. In this study, nano alumina with $98 \%$ purity and two phases of Alpha and Gamma produced by Esfarayen steel company is used (Figure 1) that their details were presented in Table 1. 


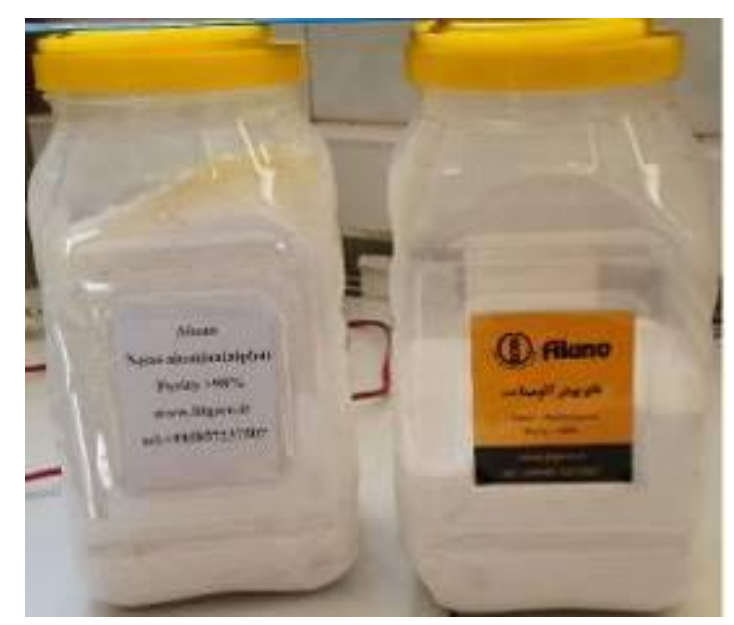

Fig.2. Alpha phase and Gamma alumina Nano powder

Table1. Specifications of Nano-alumina Alpha and Gamma phase (according to factory information)

\begin{tabular}{|c|c|c|}
\hline phase & Gamma & Alpha \\
\hline color & White powder & White powder \\
\hline Crystal structure & Cubic & HCP \\
\hline $\begin{array}{c}\text { Particle size } \\
\text { Pore size (BET) }\end{array}$ & $\begin{array}{c}\text { (bimodal) } \\
\text { (bimd } 76 \mathrm{~nm}\end{array}$ \\
\hline $\begin{array}{c}\text { Special } \\
\text { cross-sectional area } \\
\text { (BET) }\end{array}$ & $111 \frac{\mathrm{m}^{2}}{\mathrm{~g}}$ & $-\cdots--$ \\
\hline
\end{tabular}

In this research, a two-component polymer resin with the base of epoxy is used: a diglycidyle ether of bisphenol type A (DGEBA) with the commercial name of epion 828 produced by Shell Corporation as an epoxy base and a poly oxypropylene diamine with a molecular weight of 400 $\mathrm{gr} / \mathrm{mol}$ and the commercial name of Jeff Amin D 400 as a hardener.

Nano-particles with a weight ratio of $1,2,3,4,5$, and $6 \%$ are mixed with epoxy base. Glass fiber used has a two-dimensional texture and unit weight of area $200 \mathrm{gr} / \mathrm{m}^{2}$. RENLEAS QV 5Q110 wax is used to separate easily composite pieces from the die. In this study, the vacuum pump, 
C55JXHJ-4071 model, with a capacity of 142 liters per minute is used which ideally creates up to -0.82 bar vacuum.

In Table 2, the experimental program for the construction of composite samples using different percentages of Nano alumina particles with the phases of Alpha and Gamma has been presented.

Table 2: samples made with different percentages of Nano alumina particles.

\begin{tabular}{|c|c|c|c|}
\hline \multirow{4}{*}{ Alpha Phase } & code No & percentage Weight & phase \\
\cline { 2 - 4 } & 1 & 1 & Alpha \\
\cline { 2 - 4 } & 2 & 2 & Alpha \\
\cline { 2 - 4 } & 3 & 3 & Alpha \\
\cline { 2 - 4 } & 4 & 4 & Alpha \\
\cline { 2 - 4 } & 6 & 5 & Alpha \\
\cline { 2 - 4 } & 7 & 6 & Alpha \\
\cline { 2 - 4 } Gamma & 8 & 1 & Gamma \\
\cline { 2 - 4 } & 9 & 2 & Gamma \\
\cline { 2 - 4 } & 10 & 3 & Gamma \\
\cline { 2 - 4 } & 11 & 4 & Gamma \\
\cline { 2 - 4 } & 12 & 6 & --- \\
\hline \multirow{3}{*}{$\begin{array}{c}\text { Reference } \\
\text { sample }\end{array}$} & 13 & Zero & \\
\hline
\end{tabular}

\subsection{Experimental Method}

The process of making composite samples was briefly presented as follow:

1. First, the powder of Nano alumina Alpha and Gamma phase was heated inside a furnace at the temperature of $80{ }^{\circ} \mathrm{C}$ for 150 minutes and then at the temperature $120{ }^{\circ} \mathrm{C}$ for 150 minutes.

2. To produce the samples, first, alumina particles with $1,2,3,4,5$ and $6 \mathrm{wt} \%$ to the total weight of the resin were mechanically mixed. The mixture was heated to a temperature of $50{ }^{\circ} \mathrm{C}$ in a heater and then mixed and stirred for 10 minutes with the speed of $1800 \mathrm{rpm}$ speed with the epyon 818 device (Figure 3). Finally, the mixture was sonicated using a sonicator device for 30 minutes at $40{ }^{\circ} \mathrm{C}$ with the power of $150 \mathrm{kw} / \mathrm{cm}^{2}$ and the range of 5 $\mu \mathrm{m}$ (Figure 4). 


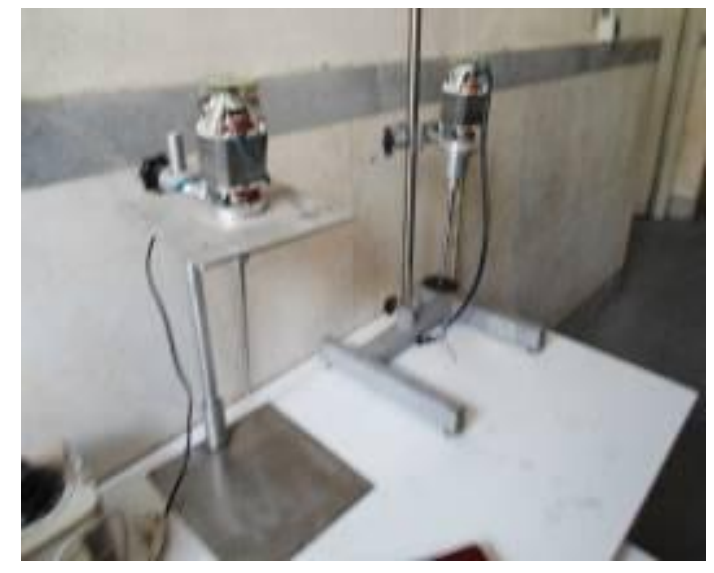

Fig.3. The Epyon Set

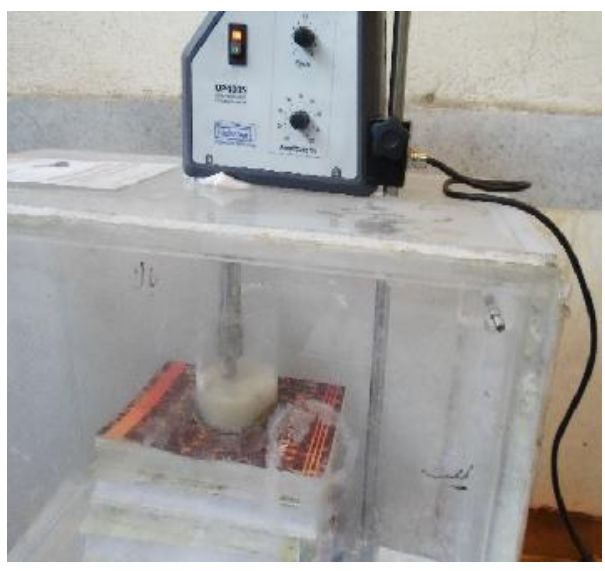

Fig.4. The sonicator

3. The mixture was poured into a beaker with a capacity of $700 \mathrm{cc}$ to be ready at room temperature for the suction process by vacuum.

4. Creating a separator layer in the die

5. The preform consists of 12 numbers of glass fiber with dimensions of $20 \times 30 \mathrm{~cm}$, a layer of Dacron fabric and a distribution layer (Figure 5).

6. By providing and connection of hydraulic system, sealing adhesive and vacuum bags, the die of resin was prepared for injection.

7. The system was connected to a vacuum pump and the injection was done under the vacuum pressure of -0.8 bar (Figure 6).

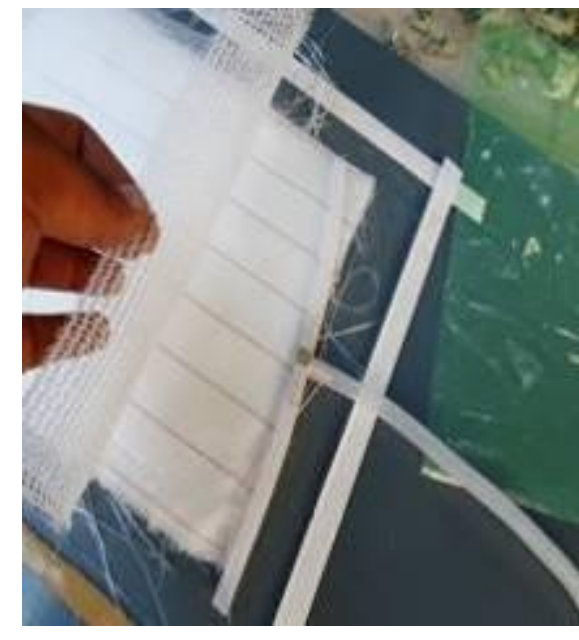

Fig.5. the distribution layer on the

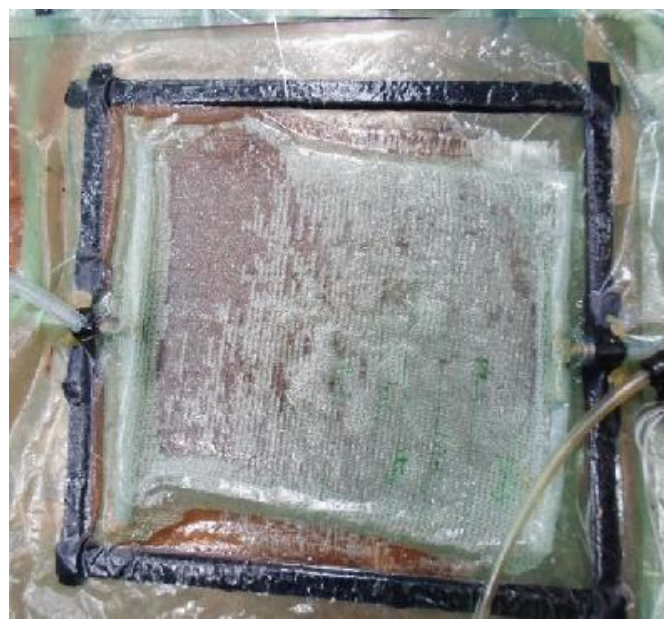

Fig.6. Injecting system

Dacron layer 
In Figure 7, samples cut by a water jet cutting have been shown.

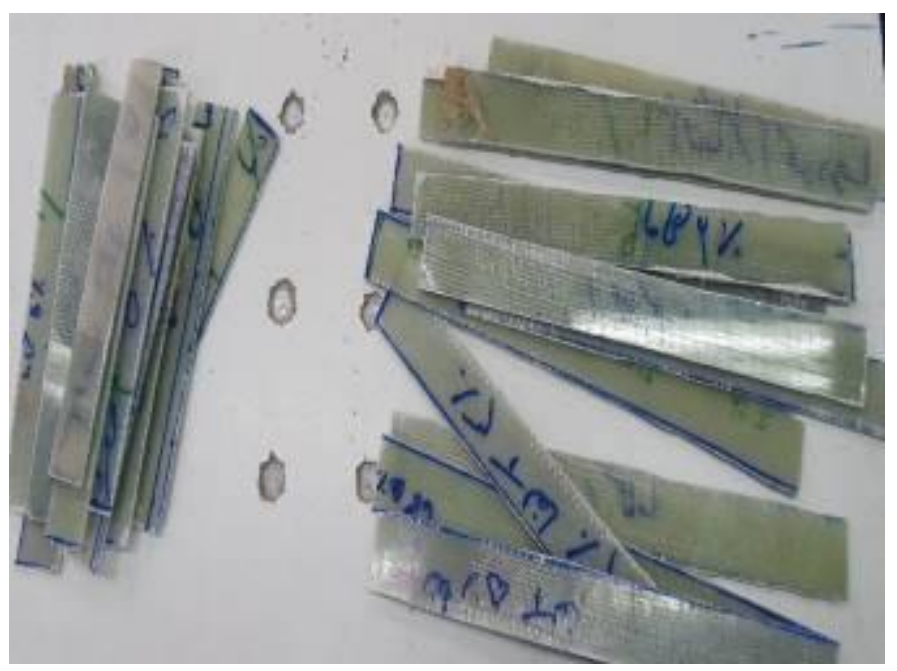

Fig.7. the samples.

\section{RESULTS AND DISCUSSION}

In this section, we study and analyze the experimental results related to the filling the die under the influence of adding nanoparticles to the fluid in order to understand the mechanism of filling the die, time and speed of the flow. Understanding the filling mechanisms of die in the process of VARTM is vitally important to prevent dry spots in the final piece and design of hydraulic systems for injection (the number of resin inputs) especially in cases where the piece has the large scale.

\subsection{The Filling Mechanism of Die}

As mentioned in this research, fibers with dimensions of $20 \times 30 \mathrm{~cm}$ and a thickness of $2.4 \mathrm{~mm}$ were put into the die as dry preforms and then a distribution layer was placed on top of the preform which upon this layer resin distribution pipes (with a diagonal cutting to the appropriate and linear distribution of resins) exist there. Vacuum pump sucked resin into the die, then resins were distributed into the pipe, passed through the distribution layer, spread throughout the area and filled the die. Figure 8 illustrates the distribution of resin and filling of the die.

To determine the position of the flow at various times as shown in Figure 9, the die were signed and diagrams of displacement-time and speed were drived. 


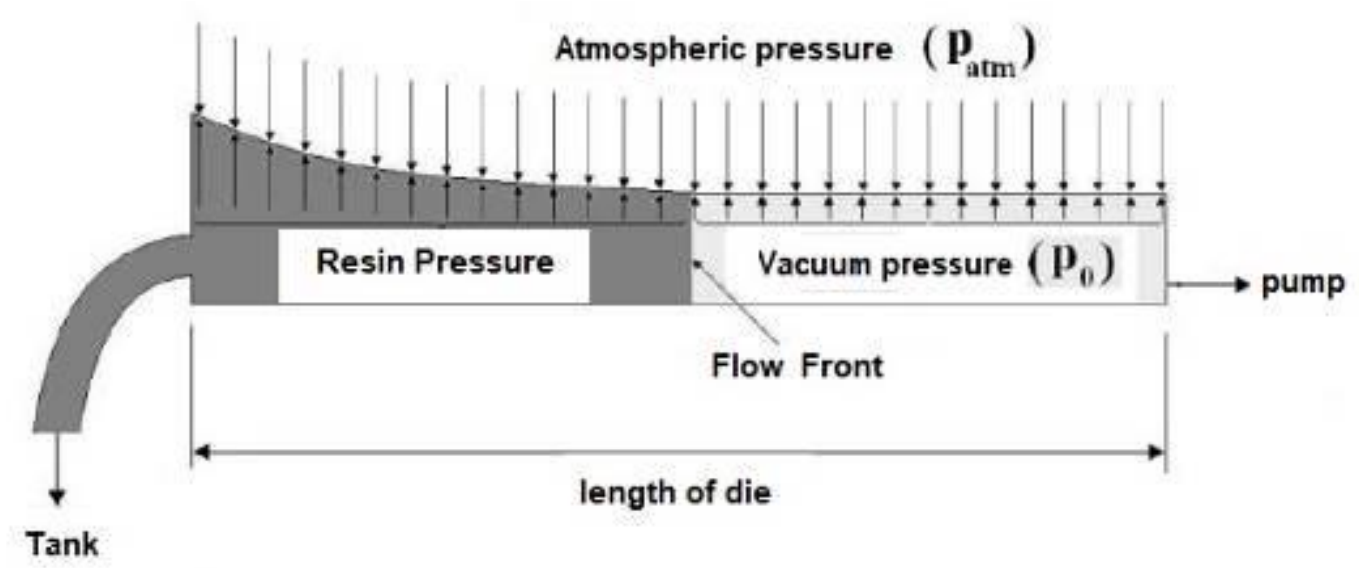

Fig.8. Schematic of filling the die and shape of flow front

To determine the position of the flow at various times as shown in Figure 9, the die were signed and diagrams of displacement-time and speed were derived.

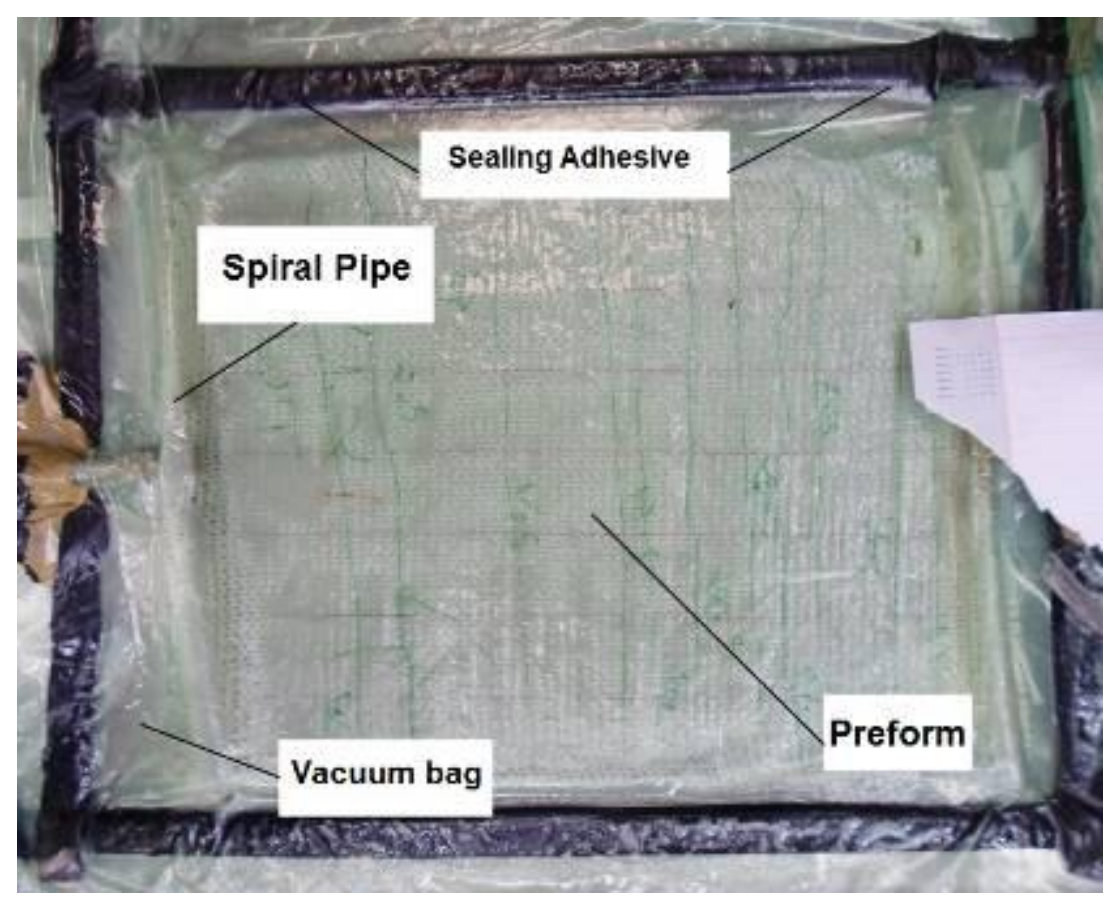

Fig.9. Schematic of a sample to measure the injection time.

\subsection{The Diagram of displacement-Time}

In this section, progress of resin in preforms for samples of 200 grams with a diameter of $8 \mathrm{~mm}$ and constant length was studied. Figure 10 depicts the experimental results related to the flow front versus to time for different percentages of Nano alumina with Alpha and Gamma phase (filling time of sample without nanoparticles is the 540 seconds). 


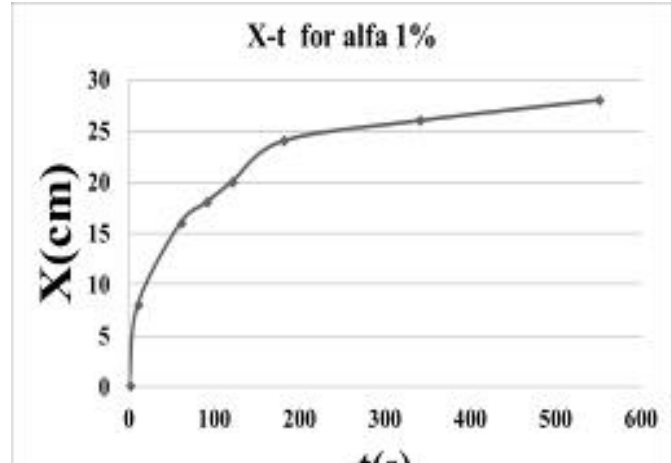

$t(s)$

displacement-time Curve Alpha 1 wt $\%$

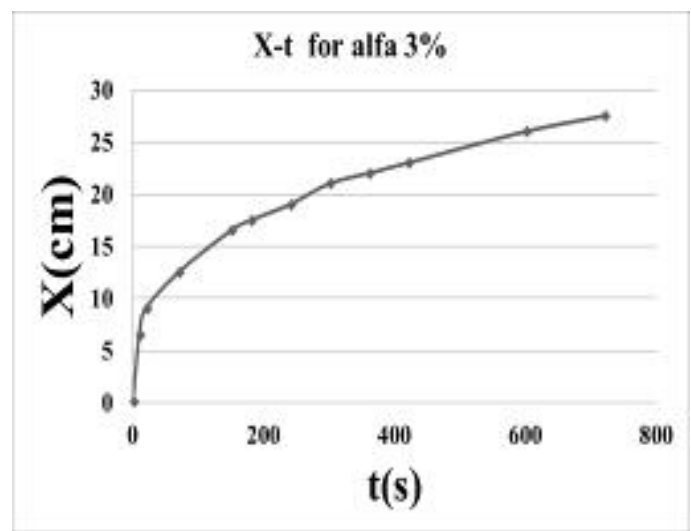

displacement-time curve for Alpha 3 $\mathrm{wt} \%$

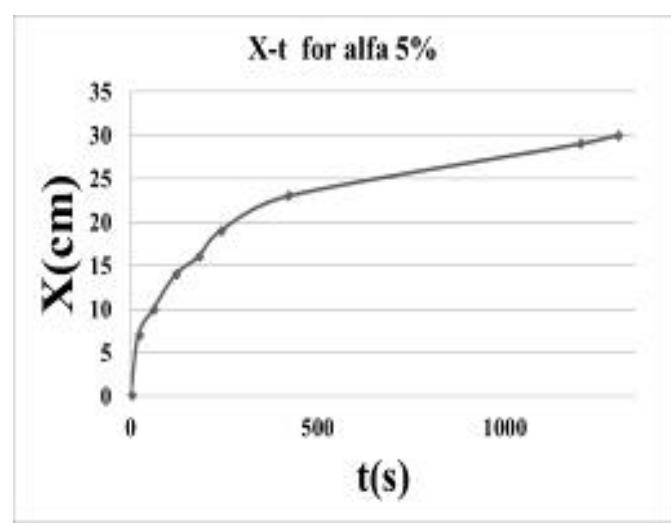

displacement-time Curve Alpha 5 wt $\%$

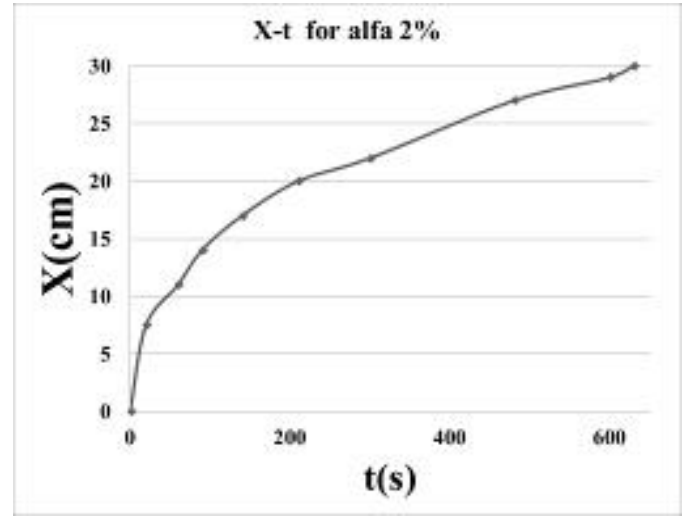

displacement-time Curve Alpha 2 wt\%

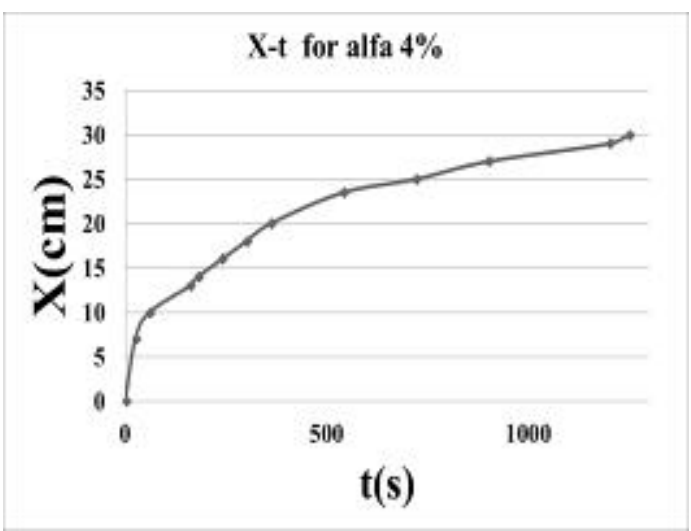

displacement-time Curve Alpha 4 wt\%

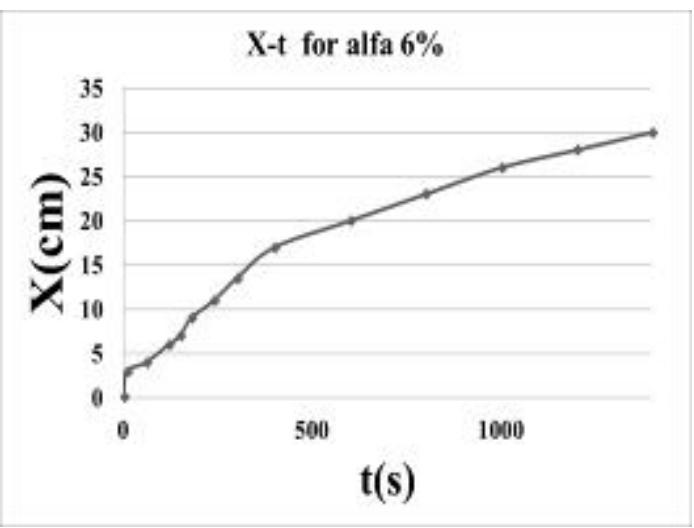

displacement-time Curve Alpha 6 wt\% 

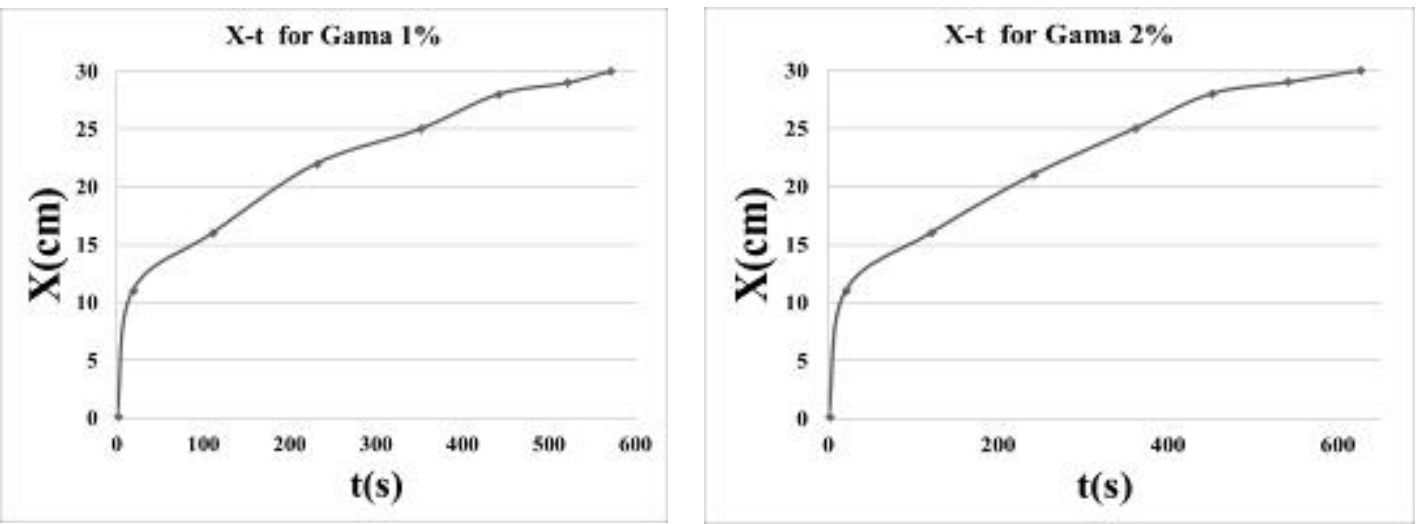

displacement-time Curve Gamma 1 wt $\%$

displacement-time Curve Gamma 2 wt $\%$
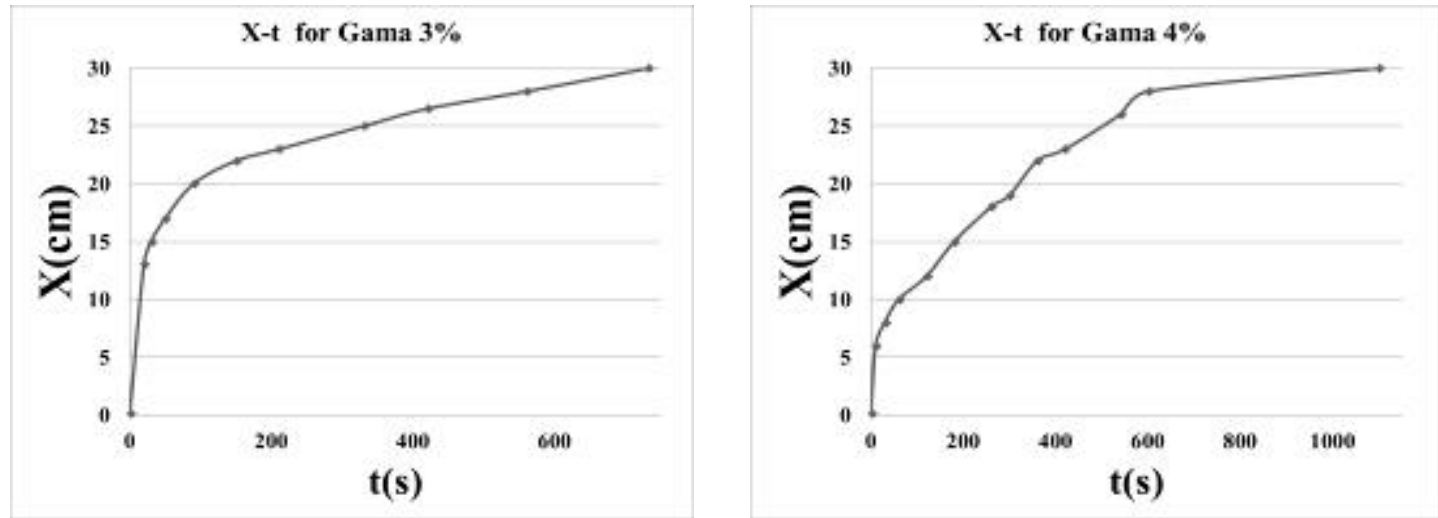

displacement-time Curve Gamma 3 wt\%

displacement-time Curve Gamma 4 wt $\%$
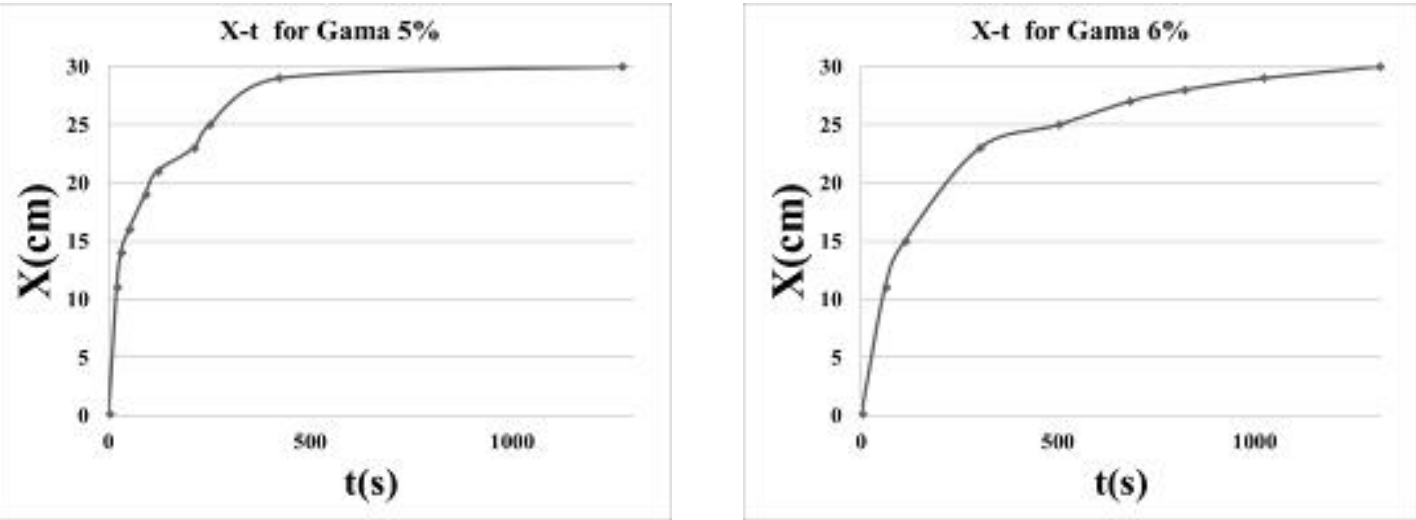

displacement-time Curve Gamma 5 wt $\%$

displacement-time Curve Gamma 6 wt\%

Fig.10. displacement-time Curve of flow front different percentages of Nano alumina.

According to the displacement-time diagrams in Figure 10, it can be found that for the composite samples with nanoparticles of alumina Alpha and Gamma grade, the speed of flow and replacement 
of resin into the die decreases by the time which means that at the initial time, resin replacement has greater improvements than at the final time of filling. This is due to increase of fluid viscosity because of the approaching gelation time and also decrease of pressure difference of resin suction into the die and consequently reduce of fluid permeability into the porous media of glass fibers.

In order to evaluate the effect of adding nanoparticles with different grades, experimental results related to making Nano composites were shown in Figures 11 and 12.

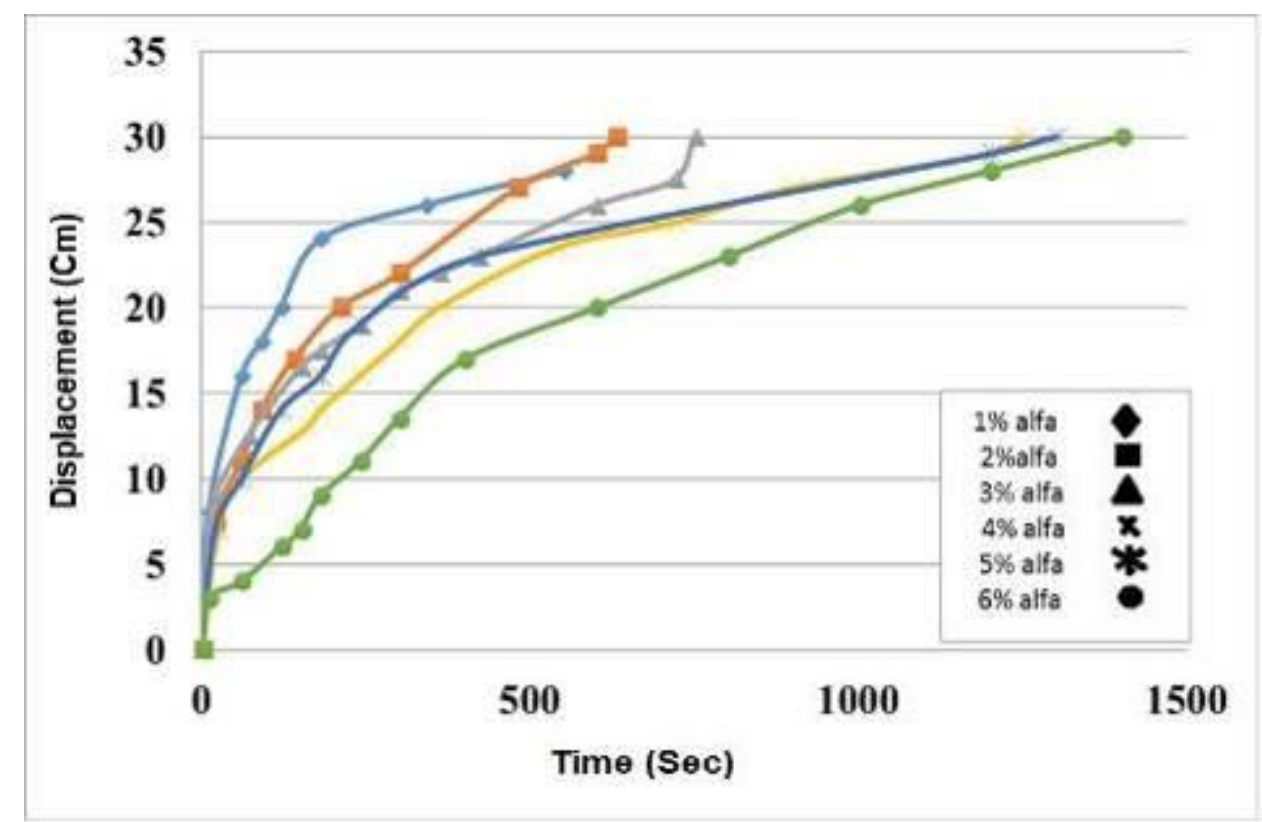

Fig.11. Comparison diagram of displacement-time for |Nano alumina, Alpha grade.

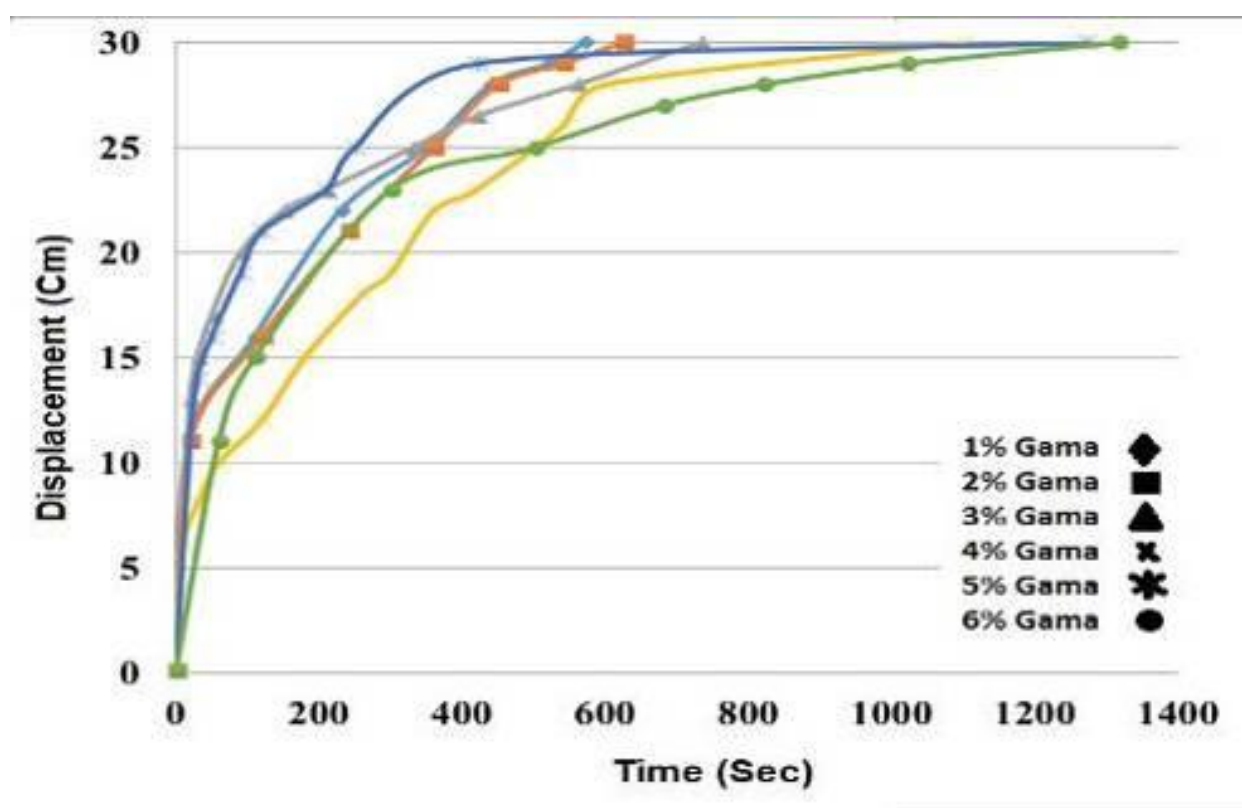

Fig.12. Comparison diagram of displacement-time for |Nano alumina, Gamma grade. 
According to the Figures 11 and 12, it can be found that the increase of the percentage of nanoparticles raises the filling time of die which caused by increasing fluid viscosity and consequently more resistance to vacuum pressure applied for moving fluid in porous media of preform. Also, it can be found that there is a considerable difference in the filling time of die in 1, 2 and $3 \mathrm{wt} \%$ of nanoparticles to the samples with 4,5 and $6 \mathrm{wt} \%$ so that filling time of sample with 4 wt $\%$ is twice the filling time of sample with $3 \mathrm{wt} \%$ while in both states particles with Alpha and Gamma grades are used. This can be a challenge in production of Nano composites samples using VARTM method, it can easily be found that in using VARTM method (in cases where the filling time of die is vitally important such as ships and planes) the addition of Nano alumina particles with more than $3 \mathrm{wt} \%$ is not proposed.

\subsection{The Diagram of Speed-Time}

In this section, the speed of resin movement (with different percentages of Nano) into the die has been studied as shown in Figures 13 and 14.

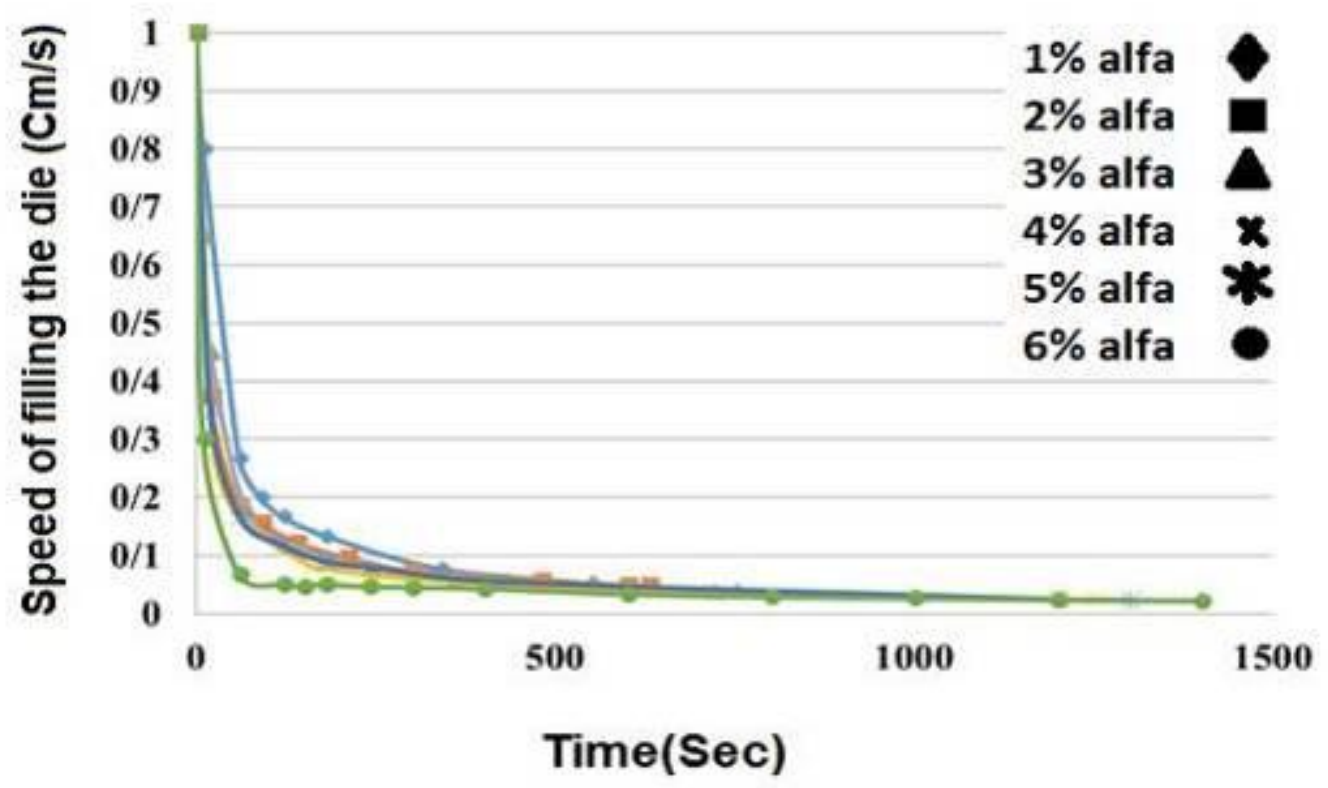

Fig.13. Comparison diagram of speed-time Nano-alumina, Alpha Phase. 


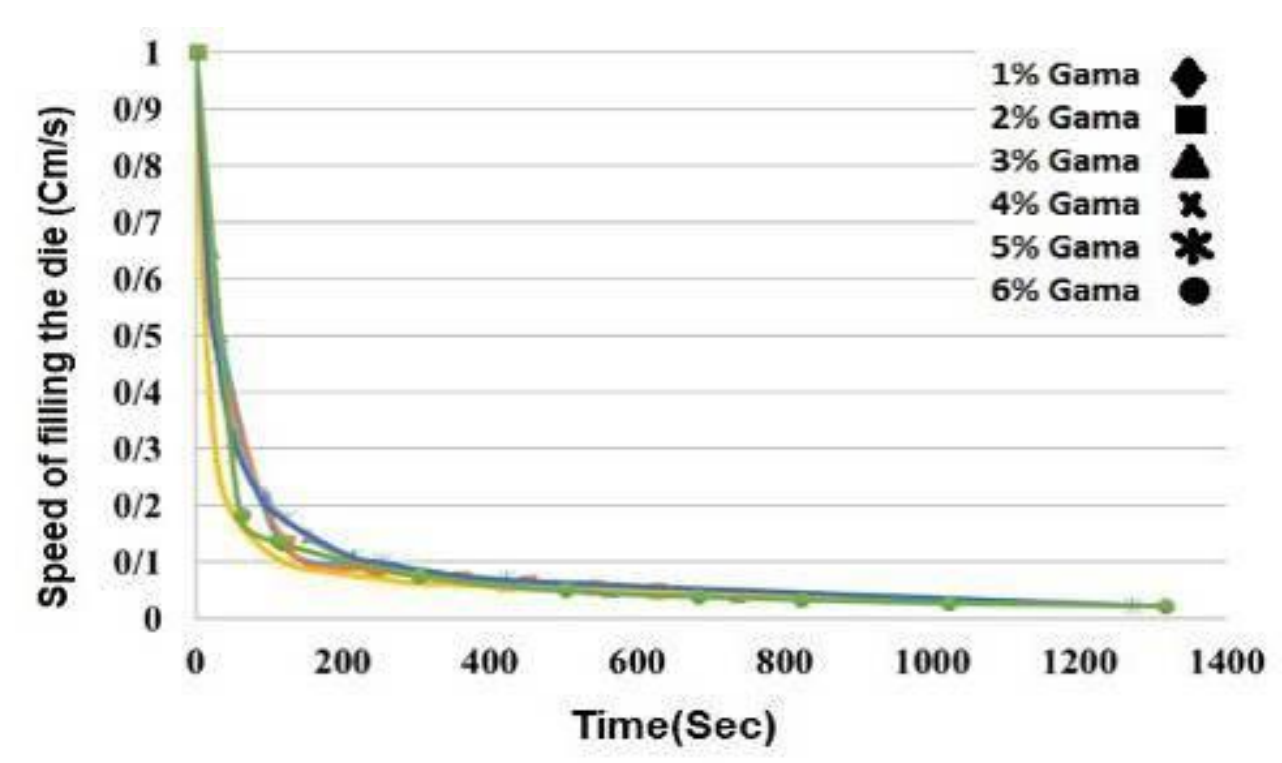

Fig.14. Comparison diagram of speed-time Nano-alumina, Gamma Phase.

As seen in speed-time diagrams of Alpha and Gamma grade samples, first, the speed of resin movement into the preform is high (about $1 \mathrm{~cm} / \mathrm{s}$ ) and then by progressing flow this speed decreases (close to zero). This is due to that by passing time, approaching the gelation time of resin and increasing the resin viscosity the created pressure difference results in less movement of resin among fiber and by progressing flow the filling time of die increases. Since the gelation time in VARTM process is a significant parameter, if the gelation is started before the filling die, resin does not reach to the all parts and consequently the piece becomes corrupted it will cause loss of time and money. Since the gelation time in VARTM process is a significant process, if the gelation is started before the filling die, resin does not reach to the all parts and the piece becomes corrupted which causes loss of time and money.

\section{CONCLUSION}

Apart from the advantages of suction method such as mechanization, good control of mechanical properties of pieces produced using suitable preform and the considerable decrease of bubbles in pieces, there are some limitations about the filling time of the die which in this research adding Nano-alumina particles to resin was studied. In general, it can be said that increasing the percentage of nanoparticles raise the filling time of die which caused by increasing fluid viscosity and consequently more resistance to the vacuum pressure 
applied for moving fluid in the porous media of preform. By increasing the percentage of nanoparticles, there is an optimal limitation to prevent the considerable increase of filling time. For Nano composite samples of alumina Alpha and Gamma grade this optimum limitation is $3 \%$.

\section{REFERENCES}

[1] Wan Y.Z, Wang Y.L., Hun Y., Zhou F.G., He B.M, Chen G.C, Han, K.Y., Moisture sorption and mechanical degradation of VARTM method three-dimensional braided carbon-epoxy composites, composites Science and Technology, 2005, 65, 1237-1243.

[2] Ghabezi, P., Golzar, M., Rajabi, J., Theoretical and experimental investigation of the effect of the injection tube diameter on mold filling time in vacuum assistant molding method (VARTM), 11th Iranian Conference on Manufacturing Engineering, 2012.

[3] Kuentzer N., Simacek P., Advani G., Walsh S., Correlation of void distribution to VARTM manufacturing techniques .composites part A: applied science and manufacturing , 2007, 38 (3).

[4] Gilbert E.N., Hayes B.S., Seferis J.C., Variable Density Composite Systems Constructed by Metal Particle Modified Prepregs, Journal of Composite Materials, 2002, 36 (17), 2045-2060.

[5] Timmerman J.F., Hayes B.S., Seferis J.C., Nanoclay reinforcement effects on the cryogenic micro-cracking of carbon fiber/epoxy composites, Composites Science and Technology, 2002, 62 (9), $1249-1258$.

[6] Yasmin A., Abot J.L., Daniel I.M., Processing of clay-epoxy nano-composites by shear mixing, Scripta Materialia; 2002, 49 (1), 81-86.

[7] Lin J.C., Chang L.C., Nien M.H., Ho H.L., Mechanical behavior of various nanoparticle filled composites at low-velocity impact, Composite Structures, 2006, 74 (1), 30-36.

[8] Rice C.C.B.P., Cloos L., Curliss D., Carbon Fiber Composites Prepared from Organoclay-Aerospace Epoxy Nano-composites, 46th International Sample Symposium and Exhibition, $2001,355-361$.

[9] Chowd hury F.H., Hosur M.V., Jeelani S., Studies on the flexural and thermo-mechanical properties of woven carbon/ Nano-clay-epoxy laminates, Materials Science and Engineering A, 2006, 421 (1-2), 298-306.

[10] Brunner A.J., Necola A., Rees M., Gasser P.H., Kornmann X., Thomann R., Barbezat M., The 
influence of silicate-based nano-filler on the fracture toughness of epoxy resin, Engineering Fracture Mechanics, 2006, 73(16), 2336-2345.

[11] Karaki T., Killgore J.P., Seferis J.C., Characterization of fatigue behavior of polynanomeric matrix composites, CD proceeding of 49th International Sample Symposium and Exhibition, 2004, 263.

[12] Gojny, F.H.; Wichmann, M.H.G.; Fiedler, B. \& Schulte, K., Influence of different carbon nanotubes on the mechanical properties of epoxy matrix composites - A comparative study. Composites Science and Technology, 2005, 65 (15-16), 2300-2313.

[13] Gilbert, E.N.; Hayes, B.S. \& Seferis, J.C., Nano-alumina modified epoxy based film adhesives. Polymer Engineering and Science, 2003, 43 (5), 1096-1104.

[14] Meguid, S.A. \& Sun, Y., On the tensile and shear strength of nano-reinforced composite interfaces. Materials and Design, 2005, 25 (4), 289-296.

[15] Zhai, L.; Ling, G.; Li, J. \& Wang, Y., The effect of nanoparticles on the adhesion of epoxy adhesive. Materials Letters, 2006, 60 (25-26), 3031-3033.

[16] Zhai, L.; Ling, G. \& Wang, Y. Effect of nano-Al2O3 on adhesion strength of epoxy adhesive and steel. International Journal of Adhesion and Adhesives, 2008, 28 (1-2), 23-28.

\section{How to cite this article:}

Ghabezi P, Farahani M, Hosseini fakhr M. Experimental Investigation Of Nano-Alumina Effect On The Filling Time In Vartm Process. J. Fundam. Appl. Sci., 2016, 8(2S), 925-940. 